\title{
A ORGANIZAÇÃO DO CONHECIMENTO NO RPG ELETRÔNICO POR MEIO DE ONTOLOGIAS
}

\author{
Samantha Alves Rodrigues dos Santos \\ Universidade Federal do Espírito Santo \\ samantha.a.santos@ufes.br \\ Marcos Luiz Cavalcanti de Miranda \\ Universidade Federal do Estado do Rio de Janeiro \\ mlmiranda@unirio.br
}

\begin{abstract}
Resumo
Investiga a Organização do Conhecimento e sua aplicação aos jogos eletrônicos, expondo os desafios e problemas desta atividade. Propõe a ontologia como uma forma de Organização do Conhecimento adequada para representar materiais nascidos no formato digital, de acordo com o paradigma da Web Semântica. Utiliza como recorte temático o estudo prático do gênero de jogos eletrônicos chamado RPG (Role-Playing Game), expondo suas características, elementos e hierarquias. Emprega como método a pesquisa exploratória, onde o conteúdo da Organização do Conhecimento é abordado, desde a definição do que é a Organização do Conhecimento, o que é o conceito, o que é um Sistema de Organização do Conhecimento e o que é uma ontologia, até a parte específica sobre os jogos eletrônicos e suas especificidades na representação. Oferece uma aplicação do conteúdo pesquisado, por meio de uma análise facetada dos jogos eletrônicos aplicada à construção de uma ontologia, sendo essa construção feita experimentalmente passo-a-passo. Aborda o potencial da ontologia ilustrando com o exemplo da aplicação da ontologia à organização dos jogos de RPG eletrônico.
\end{abstract}

Palavras-chave: Organização do Conhecimento. Ontologia. RPG. Jogo de Interpretação de Papéis. Jogo Eletrônico. RPG eletrônico. Análise Facetada. Sistemas de Organização do Conhecimento.

\section{KNOWLEDGE ORGANIZATION IN ROLE-PLAYING VIDEO GAMES THROUGH ONTOLOGIES}

\begin{abstract}
This work investigates the Knowledge Organization and its application to video games, exposing the challenges and issues in this activity. It proposes the ontology as an adequate Knowledge Organization resource to represent born- digital materials, according to the Syntactic Web paradigm. The work uses as a thematic approach the practical study of the video game genre known as RPG (Role-Playing Game), exposing its characteristics, elements and hierarchies. As a methodology, it employs exploratory research, where the Knowlegde Organization content is approached, from the definition of what is Knowledge Organization, what is a concept, what is a Knowledge Organization System and what is an ontology, until the specific part about video games and its specifics in representation. The study also offers an application of the researched content, through a facet analysis of video games applied to the creation of an ontology, while it's done experimentally step-by-step. It approaches the potential of the ontologies showing the example of the application of ontologies to the video game knowlegde organization.
\end{abstract}

Keywords: Knowledge Organization. Ontology. RPG. Role-Playing Game. Video Game. Facet Analysis. Knowledge Organization Systems. 


\section{INTRODUÇÃO}

Por muito tempo, a classificação de documentos se resumiu aos livros impressos. Contudo, novas mídias continuam a irromper e demandar organização (GNOLI, 2012), como imagens estáticas, vídeos e conteúdos nascidos em meios digitais, como é o caso dos jogos eletrônicos. Estamos em uma era envolvida por linguagens de formatos digitais que nos levam cada vez mais a um espaço comum de conhecimento universal (RESMINI, ROSATI, 2008). Novas formas de documentos surgem e, por isso, formas mais atuais e flexíveis de organizar o conhecimento terão cada vez mais espaço.

Os jogos eletrônicos (também conhecidos como videogames) já são uma parte consolidada do consumo de entretenimento da sociedade contemporânea, especialmente com o advento da democratização do acesso a computadores, Internet e dispositivos móveis. $\mathrm{O}$ setor de jogos não apenas é responsável por entretenimento, mas também se tornou uma parte importante da economia mundial ao trazer lucro, criar empregos e promover inovação (SOUZA; FREITAS, 2016).

A classificação por gêneros é utilizada amplamente como uma ferramenta de auxílio no cotidiano humano. Na literatura, na arte e em outras mídias, gêneros são utilizados para categorizar trabalhos, tendo por base critérios estilísticos, o que permite que os usuários encontrem obras de seu interesse. Desse modo, trabalhos similares são agrupados, o que permite que consumidores encontrem novos itens para consumo, o que significa que a classificação de gêneros é imperativa para editores, produtores e criadores de mídia, tendo um papel significativo no ciclo de vida da mídia, da criação ao consumo (CLARKE; LEE; CLARK, 2015).

Classificar jogos eletrônicos em gêneros é bastante útil para jogadores, pois existem inúmeros estilos que abrangem gostos diferentes de jogos eletrônicos, cada um com suas peculiaridades. Traçando um paralelo com as leis de Ranganathan (1967), é possível considerar que para todo jogo há seu jogador e para todo jogador há seu jogo. Torna-se possível observar o jogo eletrônico como uma mídia que se beneficia de uma classificação eficaz, de modo a se recuperar as obras que melhor atendam à necessidade e aos gostos do usuário, no caso, o jogador. Uma boa prática de Organização do Conhecimento também é bastante útil para os produtores e distribuidores de jogos, uma vez que isso permite que os mesmos atinjam apropriadamente o público-alvo ao qual suas obras se destinam.

Todavia, os jogos eletrônicos sofrem de um problema crônico de falta de critérios objetivos para a sua classificação, no qual dificilmente há qualquer tentativa de representação 
embasada em um viés informacional da mídia. Através do estudo dessa mídia, podemos ajudar a encontrar modos de atender melhor às diversas necessidades existentes na grande comunidade de usuários da informação que consome os jogos eletrônicos.

O trabalho acadêmico formal é frequentemente ignorado por criadores e consumidores de jogos. Algumas tentativas na direção de diminuir essa distância foram efetuadas, como a tentativa de Rolling e Adams (2003) de organizar os jogos de acordo com rótulos reconhecíveis pelos jogadores (como ação, RPG, simulação etc.) e de Apperley (2006), que enfatiza uma classificação baseada em quatro rótulos comuns de gênero: simulação, estratégia, ação e interpretação de papéis. Estes autores ressaltam a importância da elaboração de "uma base de conhecimento de jogos classificados que seja acessível para um campo maior de pesquisadores e desenvolvedores" (ELVERDAM; AARSETH, 2007).

O objetivo deste artigo é elucidar a mídia dos jogos eletrônicos como um objeto de estudo da Organização do Conhecimento (OC), apresentando a ontologia como uma estrutura em torno da qual uma base de conhecimento pode ser construída. Para alcançar esse objetivo, realizamos uma pesquisa científica exploratória, sendo efetuado um levantamento bibliográfico sobre o assunto abordado e, em seguida, uma aplicação experimental do conteúdo levantado.

\section{ORGANIZAÇÃO DO CONHECIMENTO}

A representação da realidade é um recurso utilizado pelo ser humano desde o princípio das civilizações, e pode ser descrito como "o ato de utilizar elementos simbólicos - palavras, figuras, imagens, desenhos, mímicas, esquemas, entre outros - para substituir um objeto, uma ideia ou um fato" (LIMA; ALVARES, 2012, p. 21). O conhecimento humano vem sendo representado ao longo da história através de diversas linguagens, como o sistema de contagem decimal, a comunicação oral e também a escrita, que é uma representação registrada em suportes diversos, como o papel (LIMA; ALVARES, 2012).

A importância da representação para a Ciência da Informação está em simbolizar a informação e o conhecimento, não havendo distinção entre representação e organização do conhecimento para alguns autores (LIMA; ALVARES, 2012). Portanto, a representação da informação e do conhecimento é o objeto de estudo da Organização do Conhecimento (OC).

De acordo com Lima e Alvares (2012), o esforço de representar o conhecimento gera diversos modelos de representação, que se adaptam às necessidades e especificidades de cada área. Assim, "a organização do conhecimento fornece uma metodologia por meio de 


\section{ARTIGO}

INOVAÇÃo

conceitos e suas relações, que podem ser ordenados de acordo com vários critérios" (LIMA; ALVARES, 2012, p. 30).

O ser humano tem como um processo mental habitual formar conceitos e dividi-los em grupos ou classes, agrupando-os de acordo com o que eles têm de comum e de diferente entre si. A esse processo se dá o nome de classificação (PIEDADE, 1983, p.16). De acordo com Piedade (1983, p.16), classificar é "dispor os conceitos, segundo suas semelhanças e diferenças, em certo número de grupos metodicamente distribuídos".

Um conceito é entendido como uma unidade de conhecimento (DAHLBERG, 1978a) e é o ponto de partida para estabelecer relações conceituais e a forma verbal mais adequada para representá-las. Para classificar qualquer conceito (objeto de estudo), é necessário escolher uma qualidade ou atributo que sirva de base a essa classificação. A essa qualidade, dá-se o nome de característica (PIEDADE, 1983). Uma característica de um conceito é um enunciado sobre este conceito que detenha algum elemento do mesmo (DAHLBERG, 1978a). Por exemplo, a cor verde é uma característica do objeto limão e um conjunto de características permitirão a elaboração do conceito limão.

É possível que um atributo corresponda a uma hierarquia de características, “já que o predicado de um enunciado pode tornar-se sujeito de novo enunciado e assim sucessivamente até atingirmos uma característica tão geral que possa ser considerada uma categoria" (DAHLBERG, 1978b, p. 102). Pode-se definir categoria como "um conceito de alta generalização e de grande aplicação, que pode ser empregado para reunir outros conceitos" (MILLS, 1960, p. 19). Por exemplo, é possível agrupar frutas (conceito) por categorias, como cor, tamanho, doçura, etc. Cada categoria engloba outros conceitos que apresentam seus respectivos atributos. Assim, categorias são as maiores classes de fenômenos e as mais gerais possíveis de serem formadas (PIEDADE, 1983).

Dentre as teorias de classificação, temos a teoria da classificação facetada, introduzida pela primeira vez por Ranganathan, matemático e bibliotecário indiano, em sua classificação bibliográfica intitulada Colon classification (ROSA, 1973). A análise de facetas seria "o processo mental por meio do qual são enumerados os possíveis conjuntos de características que podem formar as bases de classificação de um assunto" (RANGANATHAN, 1960, p. 28).

A abordagem de Ranganathan traz para a organização do conhecimento a categorização, ou seja, o uso de categorias para a organização de conceitos em um determinado universo de conhecimento. A noção de faceta ou categoria é utilizada para a 
“análise dos assuntos contidos nos documentos e para a organização dos componentes desses assuntos (isolados) em um esquema de classificação" (CAMPOS; GOMES, 2006, p. 355).

Ranganathan (1960) substitui as palavras categoria, gênero e espécie por faceta, foco e isolado. O exame de um assunto deve começar pelos conceitos.

Os conceitos, nesta forma desorganizada, são, frequentemente, chamados isolados.
A soma total dos isolados resultantes da divisão de um assunto por uma
característica chama-se faceta. Denominam-se focos os isolados que compõem uma
faceta, para distingui-los dos conceitos desorganizados chamados isolados
(NEEDHAM, 1971, p. 45).

De acordo com Hjørland (2008), a abordagem da classificação facetada pode ser explicada pelo seu método analítico-sintético: o termo análise se refere ao ato de "quebrar" o objeto até seus conceitos básicos e o termo síntese se refere a combinar os conceitos e unidades relevantes para descrever o objeto. A classificação facetada trata essencialmente de uma técnica, portanto, ela permite que modelos diferentes sejam desenvolvidos, atendendo a diferentes necessidades por meio de categorias e variações diferentes na sintaxe, inclusive as propriedades adicionais de objetos digitais não textuais como sons e imagens (DUARTE; CERQUEIRA, 2007). Logo, podemos escolher diferentes facetas para analisar diferentes domínios de conhecimento.

O sistema de organização do conhecimento (SOC) é um termo genérico comumente utilizado na OC para sistemas de classificação, tesauros, taxonomias, ontologias, dentre outros (SMIRAGLIA, 2014). De acordo com Hodge (2000), o termo é utilizado para englobar todos os tipos de esquemas de organização da informação e de gerenciamento do conhecimento, incluindo esquemas de categorização que organizam materiais em um nível mais geral, vocabulários altamente estruturados como tesauros e esquemas menos tradicionais como ontologias. Por serem mecanismos para organizar a informação, estão no cerne de toda biblioteca, museu e arquivo.

Segundo Hjørland (2015), em um sentido estrito, sistemas de organização do conhecimento são sinônimos para ferramentas semânticas, ou seja, seleções de conceitos e indicações de algumas das relações semânticas entre eles. Para Lima e Maculan (2017), a ontologia é considerada uma linguagem mais semanticamente rica em relação aos outros SOC, pois, além de não haver limites para as variações das relações, todas as relações entre termos podem ser explicitadas numa ontologia, inclusive as relações de equivalência e associativas. 
Neste trabalho, consideramos que o sistema de organização de conhecimento mais adequado para descrever o RPG eletrônico é a ontologia, considerando também que ela permite relações semânticas que os demais sistemas não permitem.

\section{ONTOLOGIAS}

Ontologias são sistemas de organização do conhecimento que têm sido estudados pela Ciência da Informação desde o século XIX em estudos bibliográficos para a representação de assuntos (VICKERY, 1997).

Gruber (1993) apresenta sua definição de ontologias no trecho a seguir:

Uma ontologia é uma especificação explícita de uma conceitualização. O termo é emprestado da filosofia, onde uma Ontologia é uma descrição sistemática da Existência. Para sistemas de Inteligência Artificial, o que "existe" é o que pode ser representado. Quando o conhecimento de um domínio é representado em um formalismo declarativo, esse conjunto de objetos que podem ser representados é chamado universo de discurso. Esse conjunto de objetos, e as relações descritíveis entre eles, são refletidos no vocabulário representativo com o qual um programa baseado no conhecimento representa o conhecimento. Assim, no contexto da IA, podemos descrever a ontologia de um programa definindo um conjunto de termos representativos. Nessa ontologia, definições associam os nomes de entidades no universo do discurso (ex. classes, relações, funções ou outros objetos) com um texto legível por humanos que descreva o que esses nomes significam, e axiomas formais que forcem a interpretação e bom uso desses termos. Formalmente, uma ontologia é a declaração de uma teoria lógica (GRUBER, 1993, p. 2-3).

Studer, Benjamin e Fensel (1998), a partir das definições de Gruber (1993) e Borts (1997), definem uma ontologia como uma especificação formal e explícita de uma conceitualização compartilhada; em outras palavras, a palavra conceitualização significa um modelo abstrato e simplificado de algum fenômeno do mundo real que queremos representar para algum propósito, ser explícita significa que os elementos que a compõem devem ser claramente definidos e ser formal indica que a especificação deve ser processável por máquinas (GUARINO; OBERLE; STAAB, 2009).

O primeiro autor a chamar a atenção para as ontologias no contexto da Ciência da Informação foi Vickery (1997), adotando o termo para se referir a uma representação automatizada de um determinado domínio de conhecimento (MUNN; SMITH, 2009). Desde então, as ontologias vêm sendo utilizadas no campo da Organização do Conhecimento para “apoiar a construção de estruturas categóricas para representar o conteúdo de documentos e para representar o recurso como um todo, na perspectiva de uma determinada comunidade de usuários” (ALMEIDA, 2013, 33). De acordo com Vignoli, Souto e Cervantes (2013, p. 63), 
"para representar o conhecimento, uma ontologia apresenta componentes como: conceitos, relações, funções, instâncias, axiomas".

Neste trabalho, temos interesse em construir uma ontologia para compartilhar o conhecimento comum da estrutura da informação do jogo eletrônico do gênero RPG. Atualmente existem dezenas de softwares para edição de ontologias desenvolvidos por diversas comunidades de estudo (ISOTANI; BITTENCOURT, 2015). Atualmente, o Protégé, desenvolvido pela Universidade de Stanford, é o software mais conhecido e utilizado pela comunidade internacional (ISOTANI; BITTENCOURT, 2015), motivo pelo qual o escolhemos para uso neste trabalho.

\section{O RPG ELETRÔNICO}

Para a elaboração deste estudo foi necessário um recorte temático, uma vez que o universo do conhecimento dos jogos eletrônicos é imenso e seria inviável estudá-lo em sua integralidade neste trabalho. Escolheu-se o gênero de jogos eletrônicos denominado role playing game (RPG) pelo mesmo ser, por si só, repleto de subgêneros e características distintas entre seus jogos, tornando-se um objeto de estudo bastante rico e diversificado, embora ainda delimitado.

O RPG eletrônico, ou jogo de interpretação de papéis, também é comumente chamado de C-RPG (do inglês computer RPG, RPG de computador), para diferenciá-lo dos RPG de mesa (tabletop RPG).

A criação dos RPG eletrônicos se inspira nos RPG de mesa (tabletop RPG), como o sistema publicado em 1974 nos Estados Unidos chamado Dungeons \& Dragons. Tanto os RPG de mesa quanto os de computador são altamente imersivos e inspirados por elementos de fantasia, com a criação de mundos que o jogador pode explorar, personagens com o qual pode interagir e histórias nas quais o jogador mergulha.

Pode-se diferenciar o RPG de outros gêneros de jogos:

O Role-Playing Game (RPG) surge, então, em um quadro em que o ato de jogar se encontra incluído na prática cotidiana de diversas sociedades nas mais variadas faixas etárias. E vai diferir de seus antecedentes por propor uma prática cooperativa e não competitiva entre seus participantes. Sua sigla vem do inglês e significa jogo de interpretação de papéis; foi criado nos Estados Unidos no ano 1975 e desenvolvido a partir de jogos estratégicos de guerra que simulavam batalhas em tabuleiros. De forma resumida, o jogo se baseia na premissa de que cada participante faz o papel de um personagem em uma aventura imaginária (SALDANHA; BATISTA, 2009, p. 702). 
$\mathrm{Na}$ atualidade, os jogos de RPG se estabelecem como um dos gêneros mais populares de jogos eletrônicos. De acordo com a plataforma de estatísticas para negócios Statista (2019), o RPG foi o terceiro colocado em vendas de jogos eletrônicos nos Estados Unidos no ano de 2018, sendo responsável por 11,3\% de todas as vendas do ano. A riqueza de possibilidades e elementos explorados pelo RPG, bem como sua popularidade, fazem dele uma escolha com potencial de gerar estudos relevantes na organização do conhecimento dos jogos eletrônicos.

\section{METODOLOGIA}

De modo a selecionar a literatura que embasa o trabalho, no primeiro momento realizamos um levantamento bibliográfico em bases de dados da área da Biblioteconomia e Ciência da Informação e, complementarmente, em bases de dados científicas na área da Ciência da Computação. As bases selecionadas para a pesquisa foram a Base de Dados de Periódicos em Ciência da Informação (BRAPCI), a Base de Dados de Teses e Dissertações (BDTD), a Base do Encontro Nacional de Pesquisa e Pós-Graduação em Ciência da Informação (BENANCIB), a Scientific Electronic Library Online (SciELO) e a ScienceDirect. Esta última base recuperou conteúdo relacionado à Ciência da Computação.

Utilizamos como critérios de seleção o material publicado no período entre 2000 e 2019, em língua portuguesa e inglesa. As palavras-chave utilizadas foram: Organização do Conhecimento; RPG; Jogo de Interpretação de Papéis; RPG eletrônico; Ontologias; Knowledge Organization; Role-Playing Game; RPG Online, bem como combinações entre estas.

Os resultados encontrados nas bases de dados supracitadas foram úteis para a fundamentação teórica, todavia, não recuperaram conteúdos mais expressivos sobre a Organização do Conhecimento nos jogos eletrônicos. No caso da ScienceDirect, os artigos recuperados apresentavam-se específicos demais dentro da área da Tecnologia da Informação, não sendo suficientemente úteis para a nossa pesquisa. Por esse motivo, foi necessária uma nova busca mais abrangente que pudesse recuperar resultados mais relevantes.

Para isso realizamos uma busca no mecanismo Google com as mesmas palavraschaves supracitadas e as possíveis combinações entre estas. Nessa etapa do processo foram encontrados diversos artigos científicos nos quais pudemos nos fundamentar, sendo os mais importantes os estudos da Information School da Universidade de Washington, produzidos pelo grupo de pesquisa GAME Research Group (GAMER Group). Esse grupo de pesquisa 


\section{ARTIGO}

INOVAÇÃo

realiza diversos trabalhos sobre a temática de gênero e descritores de metadados nos jogos eletrônicos, e sua produção foi empregada na nossa fundamentação teórico-metodológica.

Buscamos também embasamento teórico na literatura consagrada da Organização do Conhecimento, como nas contribuições de Mills (1960), Ranganathan (1960, 1967), Dahlberg (1979), Piedade (1983), Gruber (1993), Guarino (1995), Vickery (1997), Gnoli (2012), e Smiraglia (2014). Para fundamentarmos a escolha da ontologia neste trabalho, utilizamos artigos encontrados nas bases em que fizemos buscas e na literatura consagrada sobre ontologias, especificamente nos trabalhos de Gruber (1993) e Guarino (1995).

Tendo uma base teórica sobre a Organização do Conhecimento estabelecida, passamos a analisar os jogos eletrônicos sob a ótica da OC e, a partir dos trabalhos do GAMER Group e de outros autores, adotamos a proposta de uma análise facetada como uma fase preliminar para a organização do conhecimento nos jogos eletrônicos por meio de ontologias com base no trabalho de Lee et al. (2014).

Em seguida, escolhemos o corpo analítico para a construção da nossa ontologia. Utilizamos como recorte metodológico o gênero RPG para esta etapa. Escolhemos um corpo analítico de 30 (trinta) jogos, cujo critério de escolha está explicitado na seção 6. Com o corpo analítico escolhido, pudemos realizar uma análise facetada para organizar os conceitos relativos aos jogos escolhidos.

A seguir, construímos uma ontologia para representar o conhecimento dos jogos eletrônicos do gênero RPG. Para a consecução desta etapa, utilizamos os princípios da metodologia Ontology Development 101: a guide to creating your first ontology (NOY, MCGUINNESS, 2001), que foi escolhida por sua simplicidade de entendimento (ISOTANI; BITTENCOURT, 2015), e empregamos o software de engenharia de ontologias Protégé, desenvolvido pelo Instituto Nacional de Ciências Médicas Gerais, da Universidade de Stanford.

\section{RESULTADOS E DISCUSSÃO}

As definições e concepções atuais dos jogos eletrônicos falham ao não oferecer um conjunto concreto de características identificáveis, e essa subjetividade que traz desafios a usuários determinados a encontrar, jogar, usar e pesquisar jogos eletrônicos. Embora não exista uma classificação que encontre os ideais teóricos para satisfazer todos os usuários (CLARKE; LEE; CLARK, 2015), para ajudar nesse problema, Lee et al. (2014) propõem uma análise facetada para a classificação dos jogos eletrônicos em seu trabalho Facet Analysis of 
Video Game Genres, e identificam as múltiplas dimensões analisadas nos gêneros dos jogos por meio dela. O estudo desses autores aplica os conceitos de análise e síntese provenientes da teoria da classificação facetada de Ranganathan para identificar os tipos de informação representados nos rótulos de gênero atuais dos jogos eletrônicos.

Como resultado, foram obtidas doze facetas, cada uma representando uma característica de divisão diferente aplicada a gêneros de jogos eletrônicos, explicitados e exemplificados no quadro 1. Algumas facetas e focos foram estruturadas hierarquicamente, por exemplo: a faceta jogabilidade tem a subfaceta estilo que descreve tipos mais específicos de jogabilidades; a faceta tema tem 22 termos pais que são divididos em 127 termos filhos; e a faceta cenário foi dividida em espacial e temporal.

Os termos foram adaptados do inglês para o português, mas alguns termos foram mantidos em sua língua original por não ser usada qualquer tradução no jornalismo especializado em português, tendo como referência a versão brasileira do site IGN.

Quadro 1- Facetas de gêneros de jogos eletrônicos com exemplos de rótulos de gênero representando cada faceta

\begin{tabular}{|l|l|}
\hline \multicolumn{1}{|c|}{ Faceta } & \multicolumn{1}{c|}{ Exemplos de focos } \\
\hline Jogabilidade & Ação, luta, RPG, estratégia \\
\hline Estilo & $\begin{array}{l}\text { Sob a jogabilidade "ação" (Beat'em up, Plataforma, Ritmo) } \\
\text { Sob a jogabilidade "RPG" (Rogue-Like, JRPG, Western RPG) }\end{array}$ \\
\hline Propósito & Educação, entretenimento, festa \\
\hline Público-alvo & Todos, 12+, MA-17 \\
\hline Apresentação & 2D, 3D, baseado em ladrilho, Side-Scrolling \\
\hline Estilo artístico & Abstrato, retrô, anime \\
\hline Aspecto temporal & Tempo real, baseado em turnos \\
\hline Ponto de vista & Primeira pessoa, terceira pessoa, Overhead, perspectivas múltiplas \\
\hline Tema & $\begin{array}{l}\text { Natureza: animais, dinossauros } \\
\text { Fantasia: princesas, cavaleiros } \\
\text { Esportes: beisebol, basquetebol }\end{array}$ \\
\hline Cenário & $\begin{array}{l}\text { Espacial: cassino, aeronave, urbano } \\
\text { Temporal: medieval, moderno, futurista, steampunk }\end{array}$ \\
\hline Tom/atmosfera & Horror, humorístico, sombrio, pacífico \\
\hline Tipo de final & Finito, ramificado, sinuoso, infinito, pós-jogo \\
\hline
\end{tabular}

Fonte: Os Autores adaptado de Lee et al. (2014, p. 130-131).

O estudo de Lee et al. (2014) é uma maneira prática de aplicar a organização do conhecimento aos jogos eletrônicos, e a análise facetada feita por ela pode servir como o esqueleto para a construção de uma ontologia de jogos eletrônicos, uma vez que apresenta as classes e subclasses na hierarquia dos gêneros dos jogos eletrônicos. 


\section{ARTIGO}

INOVAÇÃo

Considerando que a ontologia é um sistema de organização do conhecimento que possui total integração com o ambiente digital no qual os jogos eletrônicos são desenvolvidos e utilizados, e por ser um sistema que prevê flexibilidade, permitindo a expansão da base de conhecimento com novos dados de forma rápida e fácil (ISOTANI; BITTENCOURT, 2015), podemos verificar que a ontologia é uma escolha interessante para ser aplicada nos jogos eletrônicos como objetos de estudo. Uma ontologia pode ser utilizada para a organização dos rótulos de gêneros de jogos eletrônicos de forma colaborativa e expansível, auxiliando o jogador a encontrar títulos que o agradem.

Escolhemos como amostra representativa do gênero RPG eletrônico, para a construção da ontologia, 30 (trinta) jogos de RPG. A amostra foi escolhida tendo como base a lista desenvolvida pelo site IGN (2019), Top 100 RPGs of All Time (em português, Melhores 100 RPGs de todos os tempos). Essa lista ordena os 100 melhores RPG existentes de acordo com a redação do site, que argumenta sobre os pontos positivos de cada um dos jogos escolhidos no artigo original. Selecionamos os 30 jogos no topo da lista, que elencamos no próximo quadro.

A escolha desta lista se dá pela grande popularidade e renome do site IGN, criado em 1996 (SCHNEIDER, 2008), e responsável por grande parte do conteúdo jornalístico de jogos atualmente. O IGN ultimamente é o site mais popular de conteúdo sobre jogos eletrônicos, tendo como base o mês de setembro de 2019, de acordo o eBizMBARank (2019), especializado em estatísticas de páginas da Web.

Quadro 2 - Amostra dos jogos de RPG eletrônico a serem utilizados na ontologia.

\begin{tabular}{|c|c|c|}
\hline Chrono Trigger (1995) & Mass Effect 2 (2012) & $\begin{array}{l}\text { The Elder Scrolls III: Morrowind } \\
\text { (2002) }\end{array}$ \\
\hline Final Fantasy VI (1994) & Dark Souls (2011) & Final Fantasy IV (1991) \\
\hline $\begin{array}{l}\text { Baldur's Gate II - Shadows of Amn } \\
(2000)\end{array}$ & Persona 4 Golden (2012) & System Shock 2 (1999) \\
\hline Pokémon Yellow (1999) & $\begin{array}{c}\text { Star Wars: Knights of the Old } \\
\text { Republic (2003) }\end{array}$ & Ultima VII: The Black Gate (1992) \\
\hline World of Warcraft (2004) & Fallout $2(1998)$ & The Elder Scrolls V: Skyrim (2011) \\
\hline Planescape: Torment (1999) & Deus Ex (2000) & Mass Effect (2007) \\
\hline Secret of Mana (1993) & Suikoden II (1999) & Bloodborne (2015) \\
\hline Diablo II (2000) & Final Fantasy Tactics (1998) & Fallout: New Vegas (2010) \\
\hline Vagrant Story (2000) & EarthBound (1995) & Monster Hunter 4 Ultimate (2013) \\
\hline The Witcher 3: Wild Hunt (2015) & $\begin{array}{c}\text { Tactics Ogre: Let Us Cling Together } \\
(1998)\end{array}$ & Pokémon Sun and Moon (2016) \\
\hline
\end{tabular}

Fonte: Os Autores adaptado de IGN (2019). 
Com a escolha da amostra concluída, fizemos uma análise facetada em cada um dos jogos incluídos na amostra, de acordo com as facetas e focos propostos por Lee et al. (2014). Não incluímos no nosso trabalho a faceta público-alvo, por se tratar de uma faceta aplicável especialmente na América do Norte devido às classificações indicativas locais, com pouca relevância para o consumidor internacional fora da comunidade norte-americana.

As facetas estilo, tema, cenário e tom/atmosfera não são descritas em sua completude no artigo original de Lee et al. (2014), devido à limitação de espaço, por conterem um grande número de focos em cada uma. O grupo de pesquisa de Lee preferiu manter o esquema completo, com todos os focos encontrados, disponível em sua página da Web. Neste trabalho utilizaremos os termos listados na página Web do grupo.

De modo a fazer a coleta dos dados e informações sobre cada faceta dos jogos, utilizamos as resenhas sobre os jogos disponíveis no site da IGN e também a plataforma de vídeos YouTube, onde pesquisamos o jogo escolhido e assistimos alguns minutos da jogabilidade de cada um e seus finais. Por questões espaciais, alocaremos os jogos da amostra em seis grupos de cinco jogos, de modo a listarmos as características representadas pelos focos que encontramos em cada jogo.

Quadro 3 - Aplicação da análise facetada, parte 1.

\begin{tabular}{|c|c|c|c|c|c|}
\hline Faceta & Chrono Trigger & Final Fantasy VI & $\begin{array}{l}\text { Baldur's Gate II: } \\
\text { Shadows of Amn }\end{array}$ & Pokémon Yellow & $\begin{array}{l}\text { World of } \\
\text { Warcraft }\end{array}$ \\
\hline Jogabilidade & RPG & RPG & RPG & RPG & RPG \\
\hline Estilo & $\begin{array}{l}\text { Japanese } \\
\quad R P G\end{array}$ & $\begin{array}{l}\text { Japanese } \\
\quad R P G\end{array}$ & $\begin{array}{l}\text { Western } \\
\text { RPG }\end{array}$ & $\begin{array}{l}\text { Japanese } \\
\qquad R P G\end{array}$ & $\begin{array}{l}\text { Massively } \\
\text { Multiplayer } \\
\text { Online RPG }\end{array}$ \\
\hline Propósito & Entretenimento & Entretenimento & Entretenimento & Entretenimento & Entretenimento, social \\
\hline Apresentação & $2 \mathrm{D}$ & $2 \mathrm{D}$ & $\begin{array}{c}3 \mathrm{D}, \\
\text { isométrico }\end{array}$ & $2 \mathrm{D}$ & $3 \mathrm{D}$ \\
\hline $\begin{array}{c}\text { Estilo } \\
\text { artístico }\end{array}$ & Anime/Mangá & Anime/Mangá & Realista & Anime/Mangá & Desenho, Realista \\
\hline $\begin{array}{l}\text { Aspecto } \\
\text { temporal }\end{array}$ & Baseado em turnos & Baseado em turnos & Tempo real & Baseado em turnos & Tempo real \\
\hline Ponto de vista & $\begin{array}{c}\text { Terceira pessoa, } \\
\text { overhead }\end{array}$ & $\begin{array}{c}\text { Terceira pessoa, } \\
\text { overhead }\end{array}$ & $\begin{array}{c}\text { Terceira pessoa, } \\
\text { overhead }\end{array}$ & $\begin{array}{c}\text { Terceira pessoa, } \\
\text { overhead }\end{array}$ & Perspectivas múltiplas \\
\hline Tema & $\begin{array}{l}\text { Viagem no tempo: } \\
\text { apocalipse, profecia }\end{array}$ & $\begin{array}{c}\text { Steampunk: } \\
\text { apocalipse, magia, } \\
\text { poder }\end{array}$ & $\begin{array}{c}\text { Alta fantasia: magia, } \\
\text { deuses, monstros }\end{array}$ & $\begin{array}{c}\text { Baixa fantasia: } \\
\text { combate, exploração, } \\
\text { animais selvagens }\end{array}$ & $\begin{array}{c}\text { Alta fantasia: magia, } \\
\text { demônios, exploração, } \\
\text { monstros }\end{array}$ \\
\hline Cenário & $\begin{array}{l}\text { Temporal: futurista, } \\
\text { pré-histórico, } \\
\text { medieval, moderno; } \\
\text { Espacial: natureza }\end{array}$ & $\begin{array}{l}\text { Temporal: imperial; } \\
\text { Espacial: castelo, } \\
\text { mina, água, ilha }\end{array}$ & $\begin{array}{l}\text { Temporal: medieval; } \\
\text { Espacial: subúrbio, } \\
\text { ilha }\end{array}$ & $\begin{array}{l}\text { Temporal: N/A; } \\
\text { Espacial: cidade, } \\
\text { natureza selvagem }\end{array}$ & $\begin{array}{l}\text { Temporal: N/A; } \\
\text { Espacial: natureza, } \\
\text { cidade }\end{array}$ \\
\hline $\begin{array}{c}\text { Tom/ } \\
\text { Atmosfera }\end{array}$ & $\begin{array}{c}\text { Aventureiro, } \\
\text { companheirismo }\end{array}$ & Aventureiro, sombrio & Sombrio, imersivo & $\begin{array}{l}\text { Aventureiro, leve, } \\
\text { fofo }\end{array}$ & $\begin{array}{c}\text { Aventureiro, } \\
\text { competitivo, imersivo, } \\
\text { companheirismo }\end{array}$ \\
\hline Tipo de Final & Ramificado & Ramificado & Finito & Finito & Infinito \\
\hline
\end{tabular}

Fonte: Os autores (2019). 
Quadro 4 - Aplicação da análise facetada, parte 2.

\begin{tabular}{|c|c|c|c|c|c|}
\hline Faceta & $\begin{array}{c}\text { Planescape: } \\
\text { Torment }\end{array}$ & Secret of Mana & Diablo II & Vagrant Story & $\begin{array}{c}\text { The Witcher 3: } \\
\text { Wild Hunt }\end{array}$ \\
\hline Jogabilidade & RPG & RPG & RPG & RPG & RPG \\
\hline Estilo & $\begin{array}{c}\text { Western } \\
\text { RPG }\end{array}$ & $\begin{array}{c}\text { Japanese } \\
R P G\end{array}$ & $\begin{array}{l}\text { Western } \\
\text { RPG }\end{array}$ & $\begin{array}{c}\text { Japanese } \\
R P G\end{array}$ & $\begin{array}{c}\text { Western } \\
\text { RPG }\end{array}$ \\
\hline Propósito & Entretenimento & Entretenimento & Entretenimento & Entretenimento & Entretenimento \\
\hline Apresentação & $\begin{array}{c}3 \mathrm{D}, \\
\text { isométrico }\end{array}$ & $2 \mathrm{D}$ & $3 \mathrm{D}$ & $3 \mathrm{D}$ & $3 \mathrm{D}$ \\
\hline $\begin{array}{c}\text { Estilo } \\
\text { artístico }\end{array}$ & Realista & Anime/mangá & Realista & Realista & Realista \\
\hline $\begin{array}{l}\text { Aspecto } \\
\text { temporal }\end{array}$ & Tempo real & Tempo real & Tempo real & Tempo real & Tempo real \\
\hline Ponto de vista & $\begin{array}{c}\text { Terceira pessoa, } \\
\text { overhead }\end{array}$ & $\begin{array}{c}\text { Terceira pessoa, } \\
\text { overhead }\end{array}$ & $\begin{array}{c}\text { Terceira pessoa, } \\
\text { overhead }\end{array}$ & Perspectivas múltiplas & Terceira pessoa \\
\hline Tema & $\begin{array}{c}\text { Fantasia sombria: } \\
\text { morte, redenção, } \\
\text { magia }\end{array}$ & $\begin{array}{c}\text { Alta fantasia: magia, } \\
\text { deuses }\end{array}$ & $\begin{array}{c}\text { Fantasia sombria: } \\
\text { demônios, anjos, } \\
\text { monstros }\end{array}$ & $\begin{array}{c}\text { Baixa fantasia: } \\
\text { monstros, magia, } \\
\text { ocultismo }\end{array}$ & $\begin{array}{c}\text { Fantasia: monstros, } \\
\text { magia }\end{array}$ \\
\hline Cenário & $\begin{array}{l}\text { Temporal: N/A; } \\
\text { Espacial: labirinto, } \\
\text { cidade }\end{array}$ & $\begin{array}{l}\text { Temporal: N/A; } \\
\text { Espacial: base militar, } \\
\text { água, natureza }\end{array}$ & $\begin{array}{c}\text { Temporal: N/A; } \\
\text { Espacial: ruínas, } \\
\text { floresta, selva, } \\
\text { castelo, sítio religioso }\end{array}$ & $\begin{array}{l}\text { Temporal: medieval; } \\
\text { Espacial: cidade, } \\
\text { caverna, minas }\end{array}$ & $\begin{array}{l}\text { Temporal: N/A; } \\
\text { Espacial: cidade, } \\
\text { natureza, ilha }\end{array}$ \\
\hline $\begin{array}{c}\text { Tom/ } \\
\text { Atmosfera }\end{array}$ & Sombrio, misterioso & Sombrio, fofo & Sombrio & Misterioso, intenso & Aventureiro, imersivo \\
\hline Tipo de Final & Ramificado & Finito & Finito & Finito & Ramificado \\
\hline
\end{tabular}

Fonte: Os autores (2019).

Quadro 5 - Aplicação da análise facetada, parte 3.

\begin{tabular}{|c|c|c|c|c|c|}
\hline Faceta & Mass Effect 2 & Dark Souls & Persona 4 Golden & $\begin{array}{l}\text { Star Wars: Knights } \\
\text { of the Old Republic }\end{array}$ & Fallout 2 \\
\hline Jogabilidade & RPG & RPG & RPG & RPG & RPG \\
\hline Estilo & $\begin{array}{l}\text { Western } \\
\text { RPG }\end{array}$ & $\begin{array}{l}\text { Western } \\
\text { RPG }\end{array}$ & $\begin{array}{l}\text { Japanese } \\
\text { RPG }\end{array}$ & $\begin{array}{l}\text { Western } \\
\text { RPG }\end{array}$ & $\begin{array}{c}\text { Western } \\
\text { RPG }\end{array}$ \\
\hline Propósito & Entretenimento & Entretenimento & Entretenimento & Entretenimento & Entretenimento \\
\hline Apresentação & $3 \mathrm{D}$ & $3 \mathrm{D}$ & $3 \mathrm{D}$ & $3 \mathrm{D}$ & $\begin{array}{c}2 \mathrm{D}, \\
\text { isométrico }\end{array}$ \\
\hline $\begin{array}{c}\text { Estilo } \\
\text { artístico }\end{array}$ & Realista & Realista & Anime/mangá & Realista & Realista \\
\hline $\begin{array}{l}\text { Aspecto } \\
\text { temporal }\end{array}$ & Tempo real & Tempo real & Tempo real & Tempo real & Tempo real \\
\hline Ponto de vista & Terceira pessoa & Terceira pessoa & Terceira pessoa & Terceira pessoa & $\begin{array}{c}\text { Terceira pessoa, } \\
\text { overhead }\end{array}$ \\
\hline Tema & $\begin{array}{l}\text { Ficção Científica: } \\
\text { alienígenas, robôs, } \\
\text { espaço, destino }\end{array}$ & $\begin{array}{l}\text { Fantasia sombria: } \\
\text { demônios, monstros, } \\
\text { profecia, magia }\end{array}$ & $\begin{array}{l}\text { Mistério: crime, } \\
\text { romance, } \\
\text { companheirismo, } \\
\text { identidade }\end{array}$ & $\begin{array}{c}\text { Ficção científica: } \\
\text { alienígenas, espaço, } \\
\text { gangue, veículos } \\
\text { aéreos }\end{array}$ & $\begin{array}{c}\text { Ficção científica: } \\
\text { distopia, apocalipse, } \\
\text { monstros, drogas, } \\
\text { robôs }\end{array}$ \\
\hline Cenário & $\begin{array}{l}\text { Temporal: futurista; } \\
\text { Espacial: espaço } \\
\text { sideral, ciberespaço, } \\
\text { veículos, base militar }\end{array}$ & $\begin{array}{l}\text { Temporal: N/A; } \\
\text { Espacial: ruínas, } \\
\text { castelo, arena }\end{array}$ & $\begin{array}{l}\text { Temporal: } \\
\text { contemporâneo; } \\
\text { Espacial: escola, } \\
\text { cidade, casa }\end{array}$ & $\begin{array}{c}\text { Temporal: N/A; } \\
\text { Espacial: espaço } \\
\text { sideral, base militar, } \\
\text { veículos }\end{array}$ & $\begin{array}{l}\text { Temporal: futurista; } \\
\text { Espacial: cidade, } \\
\text { ruínas }\end{array}$ \\
\hline $\begin{array}{c}\text { Tom/ } \\
\text { Atmosfera }\end{array}$ & Aventureiro, imersivo & Sombrio & $\begin{array}{c}\text { Aventureiro, } \\
\text { companheirismo, } \\
\text { humoroso, romântico }\end{array}$ & Aventureiro & Sombrio, solitário \\
\hline Tipo de Final & Ramificado & Ramificado & Ramificado & Ramificado & Ramificado \\
\hline
\end{tabular}

Fonte: Os autores (2019). 
Quadro 6 - Aplicação da análise facetada, parte 4.

\begin{tabular}{|c|c|c|c|c|c|}
\hline Faceta & Deus Ex & Suikoden II & $\begin{array}{l}\text { Final Fantasy } \\
\text { Tactics }\end{array}$ & EarthBound & $\begin{array}{l}\text { Tactics Ogre: Let } \\
\text { Us Cling Together }\end{array}$ \\
\hline Jogabilidade & RPG & RPG & RPG & RPG & RPG \\
\hline Estilo & $\begin{array}{c}\text { Western } \\
\text { RPG }\end{array}$ & $\begin{array}{l}\text { Japanese } \\
\text { RPG }\end{array}$ & $\begin{array}{l}\text { Japanese } \\
\text { RPG }\end{array}$ & $\begin{array}{l}\text { Japanese } \\
\text { RPG }\end{array}$ & $\begin{array}{l}\text { Japanese } \\
\text { RPG }\end{array}$ \\
\hline Propósito & Entretenimento & Entretenimento & Entretenimento & Entretenimento & Entretenimento \\
\hline Apresentação & $3 \mathrm{D}$ & $2 \mathrm{D}$ & $\begin{array}{c}3 \mathrm{D}, \\
\text { isométrico }\end{array}$ & $2 \mathrm{D}$ & $\begin{array}{c}2 \mathrm{D}, \\
\text { isométrico }\end{array}$ \\
\hline $\begin{array}{c}\text { Estilo } \\
\text { artístico }\end{array}$ & Realista & Anime/mangá & Anime/mangá & Desenho & Anime/mangá \\
\hline $\begin{array}{l}\text { Aspecto } \\
\text { temporal }\end{array}$ & Tempo real & Baseado em turnos & Baseado em turnos & Baseado em turnos & Baseado em turnos \\
\hline Ponto de vista & Primeira pessoa & $\begin{array}{l}\text { Terceira pessoa, } \\
\text { overhead }\end{array}$ & $\begin{array}{l}\text { Terceira pessoa, } \\
\text { overhead }\end{array}$ & Terceira pessoa & $\begin{array}{l}\text { Terceira pessoa, } \\
\text { overhead }\end{array}$ \\
\hline Tema & $\begin{array}{c}\text { Cyberpunk: distopia, } \\
\text { alienígenas, } \\
\text { conspiração, } \\
\text { pandemia }\end{array}$ & $\begin{array}{c}\text { Baixa fantasia: } \\
\text { mercenários, magia, } \\
\text { militar }\end{array}$ & $\begin{array}{l}\text { Fantasia: magia, } \\
\text { militar, vingança, } \\
\text { mercenários, fé }\end{array}$ & $\begin{array}{l}\text { Mistério: alienígenas, } \\
\text { robôs, magia }\end{array}$ & $\begin{array}{l}\text { Fantasia: poder, } \\
\text { liberdade, política }\end{array}$ \\
\hline Cenário & $\begin{array}{l}\text { Temporal: futurista; } \\
\text { Espacial: cidade, } \\
\text { prisão }\end{array}$ & $\begin{array}{c}\text { Temporal: N/A; } \\
\text { Espacial: cidade, base } \\
\text { militar }\end{array}$ & $\begin{array}{l}\text { Temporal: medieval; } \\
\text { Espacial: cidade, } \\
\text { natureza, sítio } \\
\text { religioso }\end{array}$ & $\begin{array}{l}\text { Temporal: N/A; } \\
\text { Espacial: cidade, } \\
\text { natureza selvagem }\end{array}$ & $\begin{array}{l}\text { Temporal: medieval; } \\
\text { Espacial: cidade } \\
\text { castelo, ilha }\end{array}$ \\
\hline $\begin{array}{c}\text { Tom/ } \\
\text { Atmosfera }\end{array}$ & Sombrio, Misterioso & Aventureiro & Aventureiro & Sombrio, Solitário & Aventureiro \\
\hline Tipo de final & Ramificado & Ramificado & Finito & Finito & Ramificado \\
\hline
\end{tabular}

Fonte: Os autores (2019).

Quadro 7 - Aplicação da análise facetada, parte 5.

\begin{tabular}{|c|c|c|c|c|c|}
\hline Faceta & $\begin{array}{l}\text { The Elder Scrolls } \\
\text { III: Morrowind }\end{array}$ & Final Fantasy IV & System Shock 2 & $\begin{array}{c}\text { Ultima VII: } \\
\text { The Black Gate }\end{array}$ & $\begin{array}{c}\text { The Elder Scrolls V: } \\
\text { Skyrim }\end{array}$ \\
\hline Jogabilidade & RPG & RPG & RPG & RPG & RPG \\
\hline Estilo & $\begin{array}{l}\text { Western } \\
\text { RPG }\end{array}$ & $\begin{array}{l}\text { Japanese } \\
\text { RPG }\end{array}$ & $\begin{array}{c}\text { Western } \\
\text { RPG }\end{array}$ & $\begin{array}{c}\text { Western } \\
\text { RPG }\end{array}$ & $\begin{array}{c}\text { Western } \\
\text { RPG }\end{array}$ \\
\hline Propósito & Entretenimento & Entretenimento & Entretenimento & Entretenimento & Entretenimento \\
\hline Apresentação & $3 \mathrm{D}$ & $2 \mathrm{D}$ & $3 \mathrm{D}$ & $2 \mathrm{D}$ & $3 \mathrm{D}$ \\
\hline $\begin{array}{c}\text { Estilo } \\
\text { artístico }\end{array}$ & Realista & Anime/mangá & Realista & Desenho & Realista \\
\hline $\begin{array}{l}\text { Aspecto } \\
\text { temporal }\end{array}$ & Tempo real & Baseado em turnos & Tempo real & Tempo real & Tempo real \\
\hline Ponto de vista & Primeira pessoa & $\begin{array}{l}\text { Terceira pessoa, } \\
\text { overhead }\end{array}$ & Primeira pessoa & $\begin{array}{c}\text { Terceira pessoa, } \\
\text { overhead }\end{array}$ & Perspectivas múltiplas \\
\hline Tema & $\begin{array}{l}\text { Fantasia: deuses, } \\
\text { profecia, poder }\end{array}$ & $\begin{array}{l}\text { Alta Fantasia: magia, } \\
\text { poder, romance }\end{array}$ & $\begin{array}{c}\text { Ficção científica: } \\
\text { distopia, alienígenas, } \\
\text { espaço }\end{array}$ & $\begin{array}{l}\text { Fantasia: apocalipse, } \\
\text { mistério, magia }\end{array}$ & $\begin{array}{c}\text { Fantasia: eragões, } \\
\text { profecia, magia }\end{array}$ \\
\hline Cenário & $\begin{array}{l}\text { Temporal: medieval; } \\
\text { Espacial: ilha, cidade, } \\
\text { castelo, casa, natureza }\end{array}$ & $\begin{array}{c}\text { Temporal: N/A; } \\
\text { Espacial: cidade, } \\
\text { castelo, espaço sideral }\end{array}$ & $\begin{array}{c}\text { Temporal: futurista; } \\
\text { Espacial: espaço } \\
\text { sideral, ciberespaço, } \\
\text { laboratório científico }\end{array}$ & $\begin{array}{l}\text { Temporal: N/A; } \\
\text { Espacial: ilha, cidade, } \\
\text { subúrbio, castelo }\end{array}$ & $\begin{array}{l}\text { Temporal: medieval; } \\
\text { Espacial: ilha, cidade, } \\
\text { castelo, casa, natureza } \\
\text { selvagem, planície, } \\
\text { área rural }\end{array}$ \\
\hline $\begin{array}{c}\text { Tom/ } \\
\text { Atmosfera }\end{array}$ & Aventureiro & Aventureiro & $\begin{array}{l}\text { Horror, } \\
\text { sombrio, } \\
\text { misterioso }\end{array}$ & $\begin{array}{l}\text { Aventureiro, } \\
\text { misterioso }\end{array}$ & Aventureiro \\
\hline Tipo de final & Finito & Ramificado & Finito & Ramificado & Infinito \\
\hline
\end{tabular}

Fonte: Os autores (2019). 
Quadro 8 - Aplicação da análise facetada, parte 6.

\begin{tabular}{|c|c|c|c|c|c|}
\hline Faceta & Mass Effect & Bloodborne & Fallout: New Vegas & $\begin{array}{c}\text { Monster Hunter } 4 \\
\text { Ultimate }\end{array}$ & $\begin{array}{c}\text { Pokémon Sun and } \\
\text { Moon }\end{array}$ \\
\hline Jogabilidade & RPG & RPG & RPG & RPG & RPG \\
\hline Estilo & $\begin{array}{l}\text { Western } \\
\text { RPG }\end{array}$ & $\begin{array}{l}\text { Western } \\
\text { RPG }\end{array}$ & $\begin{array}{l}\text { Western } \\
\text { RPG }\end{array}$ & $\begin{array}{l}\text { Western } \\
\text { RPG }\end{array}$ & $\begin{array}{c}\text { Japanese } \\
\text { RPG }\end{array}$ \\
\hline Propósito & Entretenimento & Entretenimento & Entretenimento & Entretenimento & Entretenimento \\
\hline Apresentação & $3 \mathrm{D}$ & $3 \mathrm{D}$ & $3 \mathrm{D}$ & $3 \mathrm{D}$ & $3 \mathrm{D}$ \\
\hline $\begin{array}{c}\text { Estilo } \\
\text { artístico }\end{array}$ & Realista & Realista & Realista & Realista & Anime/mangá \\
\hline Aspecto Temporal & Tempo real & Tempo real & Tempo real & Tempo real & Baseado em turnos \\
\hline Ponto de vista & Terceira pessoa & Terceira pessoa & Perspectivas múltiplas & Terceira pessoa & $\begin{array}{c}\text { Terceira pessoa, } \\
\text { overhead }\end{array}$ \\
\hline Tema & $\begin{array}{l}\text { Ficção científica: } \\
\text { alienígenas, robôs, } \\
\text { espaço, destino }\end{array}$ & $\begin{array}{c}\text { Fantasia sombria: } \\
\text { demônios, monstros, } \\
\text { deuses }\end{array}$ & $\begin{array}{l}\text { Ficção científica: } \\
\text { distopia, apocalipse, } \\
\text { robôs, poder }\end{array}$ & $\begin{array}{c}\text { Baixa fantasia: } \\
\text { monstros, combate, } \\
\text { exploração, animais } \\
\text { selvagens }\end{array}$ & $\begin{array}{c}\text { Baixa fantasia: } \\
\text { combate, exploração, } \\
\text { animais selvagens }\end{array}$ \\
\hline Cenário & $\begin{array}{c}\text { Temporal: futurista; } \\
\text { Espacial: espaço } \\
\text { sideral, ciberespaço, } \\
\text { veículos, base militar }\end{array}$ & $\begin{array}{l}\text { Temporal: N/A; } \\
\text { Espacial: ruínas, sítio } \\
\text { religioso, floresta }\end{array}$ & $\begin{array}{l}\text { Temporal: futurista; } \\
\text { Espacial: cidade, } \\
\text { natureza selvagem }\end{array}$ & $\begin{array}{l}\text { Temporal: N/A; } \\
\text { Espacial: natureza } \\
\text { selvagem }\end{array}$ & $\begin{array}{l}\text { Temporal: N/A; } \\
\text { Espacial: cidade, } \\
\text { natureza selvagem }\end{array}$ \\
\hline $\begin{array}{c}\text { Tom/ } \\
\text { Atmosfera }\end{array}$ & Aventureiro, imersivo & $\begin{array}{l}\text { Horror, } \\
\text { sombrio, } \\
\text { intenso }\end{array}$ & $\begin{array}{l}\text { Aventureiro, } \\
\text { misterioso }\end{array}$ & Aventureiro & $\begin{array}{l}\text { Aventureiro, } \\
\text { leve, } \\
\text { fofo }\end{array}$ \\
\hline Tipo de Final & Ramificado & Ramificado & Ramificado & Finito & Finito \\
\hline
\end{tabular}

Fonte: Os autores (2019).

Após a coleta das características dos jogos da nossa amostra, seguimos para a construção da ontologia, aplicando as facetas e focos encontrados.

\section{CONTRUÇÃO DA ONTOLOGIA}

Dentre as possíveis definições de ontologias existentes na literatura, Noy e McGuinness (2001) buscam desenvolver a sua própria para ajudar a entender os diferentes componentes práticos da construção da ontologia. Portanto, para os efeitos práticos, uma ontologia é uma descrição explícita e formal de conceitos em um domínio de discurso (os conceitos são as classes), propriedades de cada conceito descrevendo os vários recursos e atributos do conceito (também conhecidos como slots), e restrições nas propriedades. Uma ontologia agrupada com um conjunto de instâncias individuais de classes constitui uma base de conhecimento.

As classes são o foco na maioria das ontologias, e elas descrevem os conceitos nos domínios. No exemplo da ontologia de jogos eletrônicos, uma classe de jogos representaria todos os jogos, e um jogo específico seria uma instância dessa classe. Um jogo de ação é uma instância da classe de jogos de ação. Adicionalmente, uma classe pode ter subclasses que representam os conceitos mais específicos que a superclasse. 
$\mathrm{Na}$ construção da ontologia, organizamos hierarquicamente o resultado da análise facetada que realizamos. Obtivemos o resultado que se encontra listado abaixo e ilustrado na Figura 1, transformando as facetas em classes:

Figura 1 - Definição das classes.

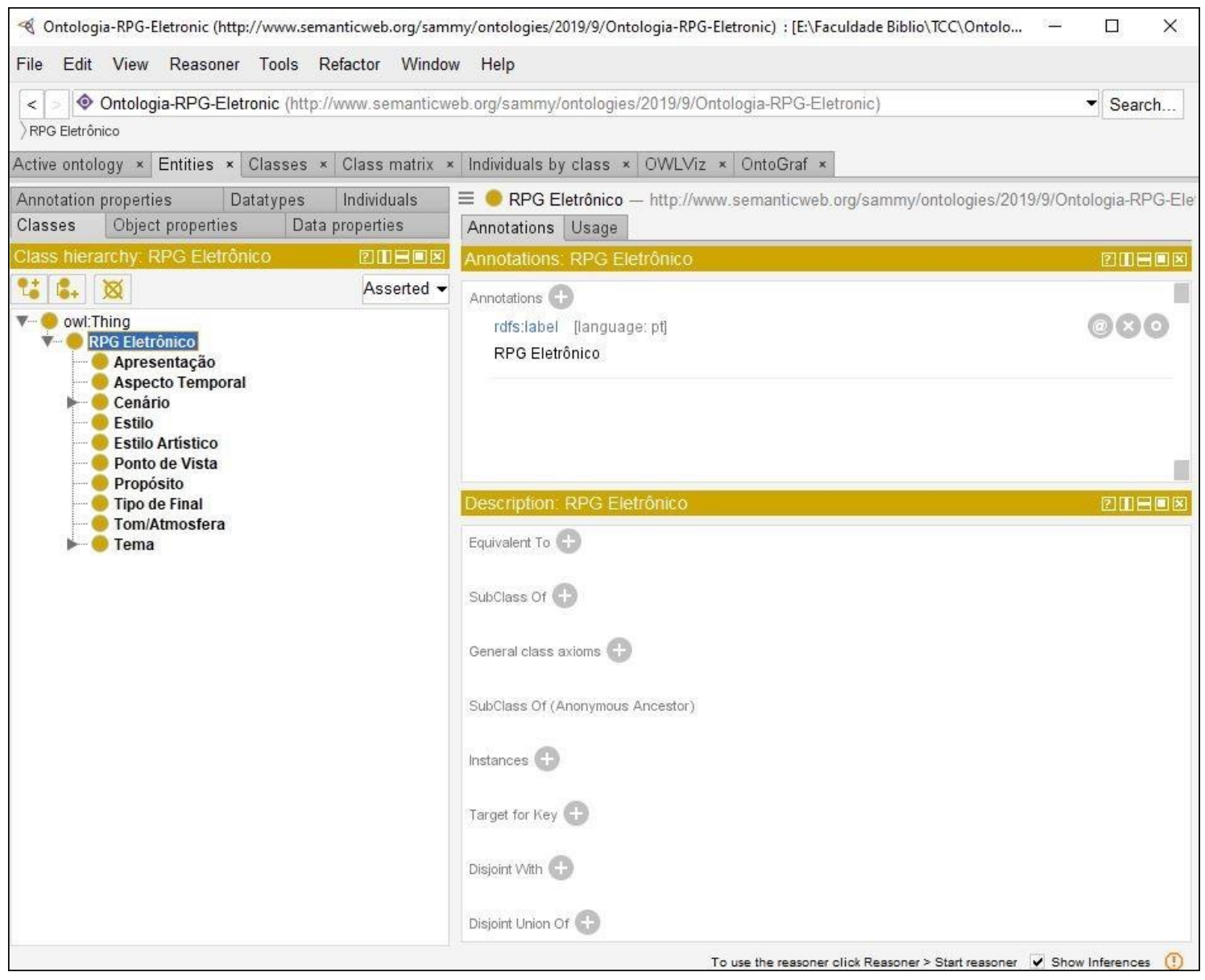

Fonte: Os autores (2019).

Em seguida, determinamos a estrutura interna dos conceitos provenientes da nossa análise facetada. Para cada uma das facetas, criamos uma propriedade de modo a representar um relacionamento entre as entidades da ontologia.

Chegamos a um total de 10 (dez) propriedades, ilustradas abaixo:

- ÉUmTipoDe: Aplica-se para a classe estilo;

- TemComoPropósito: Aplica-se para a classe propósito;

- SePassaEm: Aplica-se para as classes apresentação, aspecto temporal;

- TemEstiloArtístico: Aplica-se para a classe estilo artístico;

- TemPontodeVista: Aplica-se para a classe ponto de vista;

- TrataDe: Aplica-se para a classe tema e subclasse subtema; 
- TemCenárioTemporal: Aplica-se para a classe cenário, subclasse temporal;

- TemCenárioEspacial: Aplica-se para a classe cenário, subclasse espacial;

- TemTomOuAtmosfera: Aplica-se para a classe tom/atmosfera;

- TemTipoDeFinal: Aplica-se à classe tipo de final.

Figura 2 - Definição das propriedades.

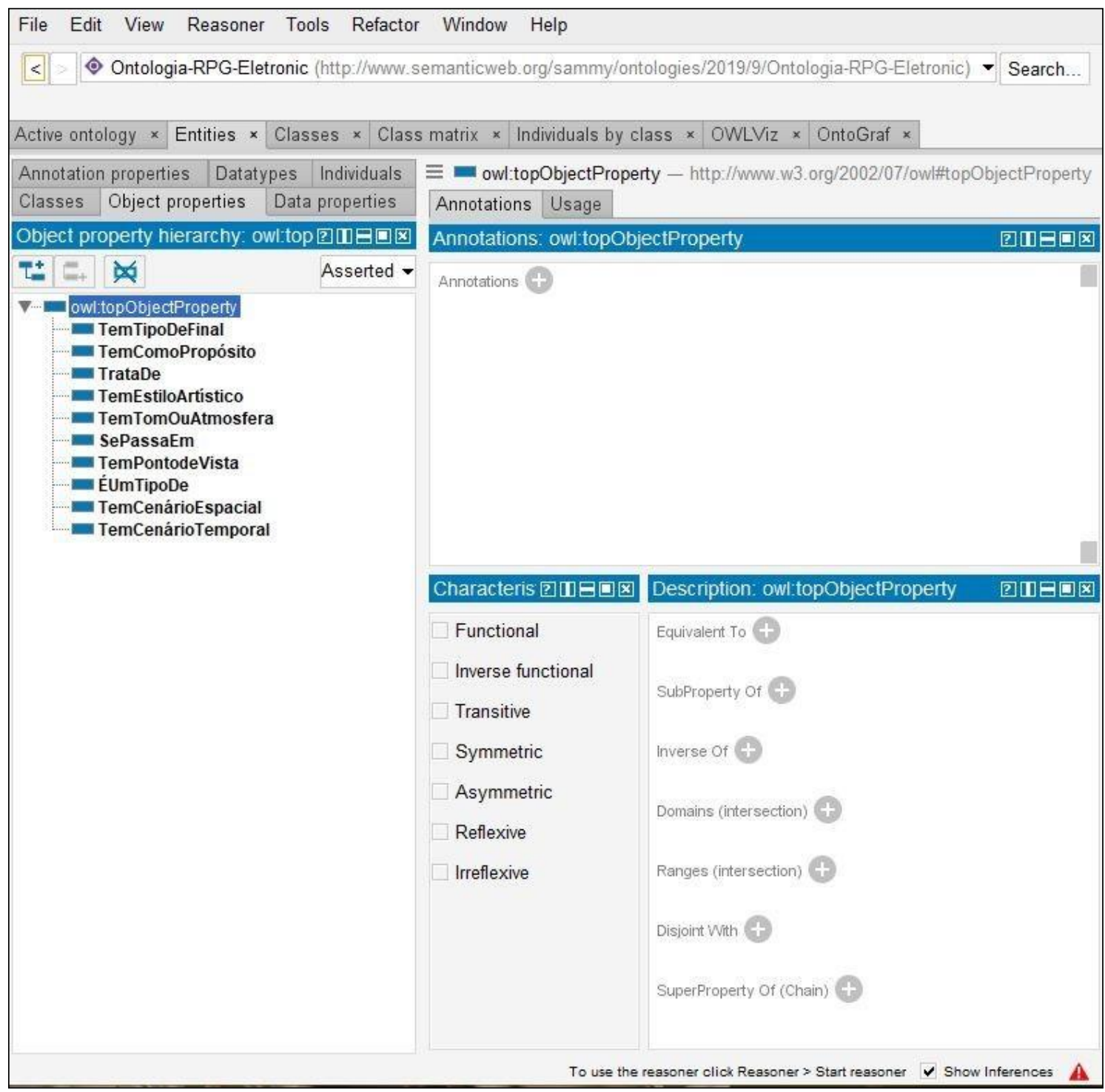

Fonte: Os autores (2019).

$\mathrm{Na}$ terceira etapa definimos as restrições das propriedades. As restrições são os valores que elas podem apresentar, por exemplo, no caso da propriedade TemTipoDeFinal, os indivíduos pertencentes à classe tipo de final são os valores permitidos, no caso, finito, infinito e ramificado.

$\mathrm{Na}$ quarta etapa da construção da ontologia, incluímos as instancias; no nosso caso, os jogos de RPG eletrônico escolhidos como amostra e os focos extraídos na análise facetada:

P2P \& INOVAÇÃO, Rio de Janeiro, v. 7, n. 1, p. 107-131, set. 2020/fev. 2021. 
Figura 3: Definição das instâncias da ontologia.

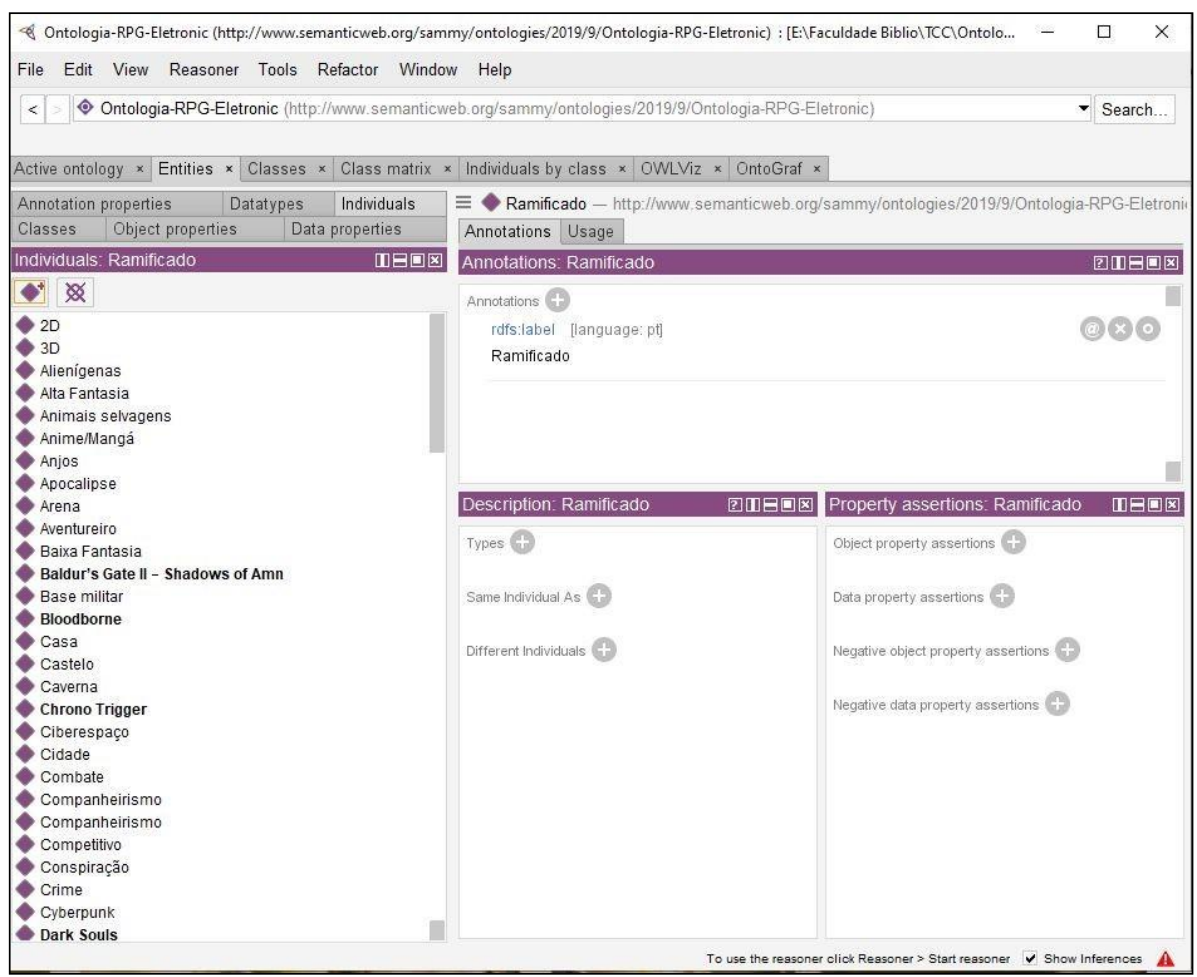

Fonte: Os autores (2019).

Em seguida, alocamos cada um dos indivíduos em suas classes pertencentes.

Figura 4 - Alocação dos indivíduos em classes.

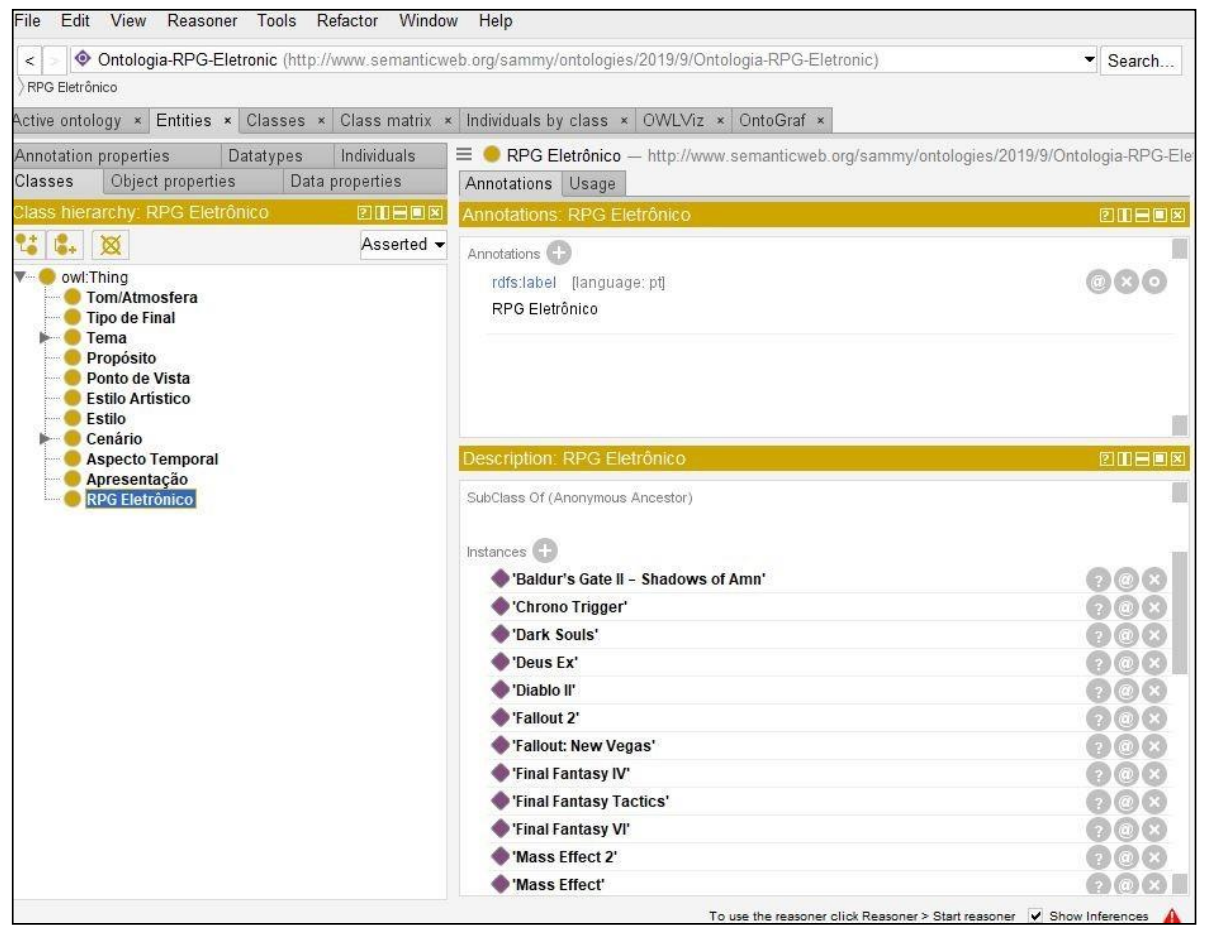

Fonte: Os autores (2019).

P2P \& INOVAÇÃO, Rio de Janeiro, v. 7, n. 1, p. 107-131, set. 2020/fev. 2021. 
$\mathrm{Na}$ etapa final da construção da ontologia, explicitamos os relacionamentos entre as entidades da ontologia com base nas propriedades:

Figura 5 - Definição das propriedades.

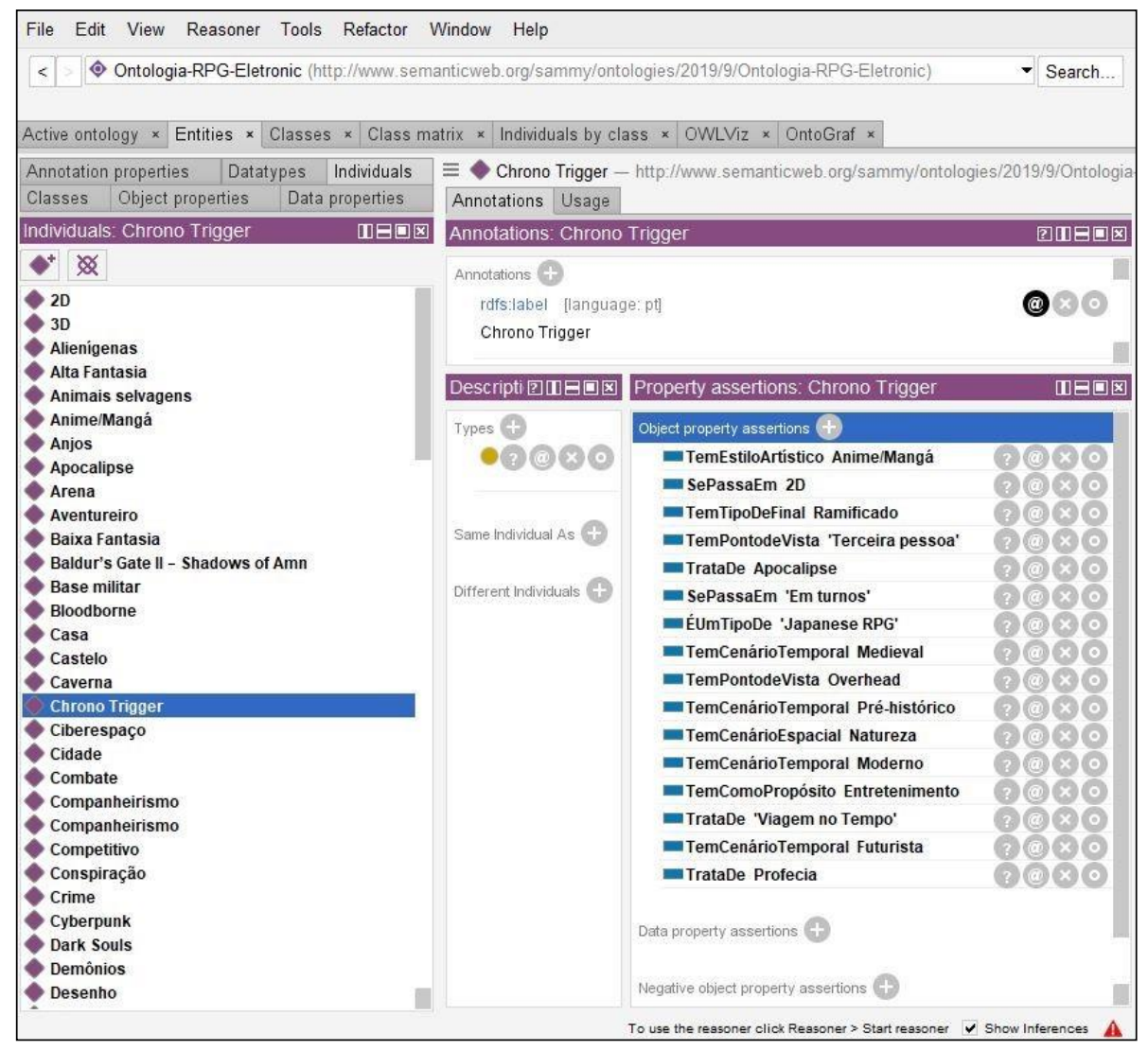

Fonte: Os autores (2019).

Obtivemos como resultado final a seguinte representação da ontologia para estudo de gênero dos jogos eletrônicos:

Figura 6 - Representação visual parcial da ontologia, com visualização do plugin OntoGraf.

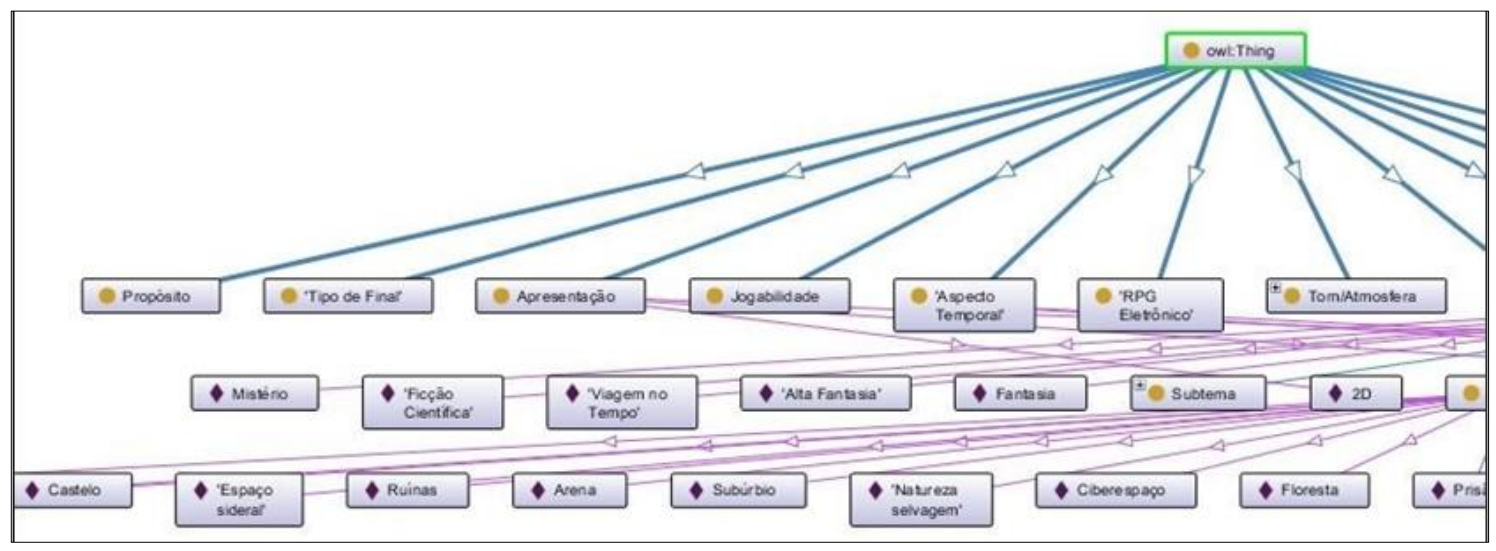

Fonte: Os autores (2019). 
A representação visual do software Protégé prioriza as relações do tipo gêneroespécie, enquanto as demais relações, embora devidamente incluídas e adicionadas à ontologia, não aparecem na visualização final. Portanto, a representação visual final da ontologia se assemelha a uma taxonomia, sendo facilmente observadas as relações genéricas entre os conceitos nessa representação.

\section{CONSIDERAÇÕES FINAIS}

A Organização do Conhecimento e as atividades concernentes a ela, como a representação descritiva e temática, estão no cerne da atividade da maioria dos profissionais da informação. Mesmo que não trabalhemos diretamente com ela, o acesso à informação depende desta atividade. Uma organização eficaz significa uma recuperação eficiente da informação.

Os profissionais da informação devem estar preparados para explorar todo o potencial das novas mídias e tecnologias, e também para entenderem e contornarem os desafios delas advindos. Ainda engatinhamos na descrição de materiais que fogem dos padrões bibliográficos de suporte em papel, e devemos estar atentos para o que uma representação inadequada pode causar. Ainda não conseguimos resolver totalmente a questão dos pontos de acesso a esses materiais.

O jogo eletrônico é um grande exemplo dessa situação, pois há muitas dificuldades para estabelecer o controle de um vocabulário que descreva os gêneros dos jogos, uma vez que o padrão comercial é não ter qualquer padrão. Em acréscimo, as tentativas de inserir uma perspectiva acadêmica nesse assunto não se mostraram frutíferas. Por esse motivo, pudemos verificar a importância do uso de um esquema de classificação facetada em jogos eletrônicos específicos para essa mídia, considerando suas particularidades e desafios, e apresentando uma proposta expansível e adaptável.

Como jogos eletrônicos sofrem muitas mudanças e novos jogos são lançados com frequência, e considerando a possibilidade de criação de novos gêneros, tecnologias e exemplares, as características expansivas e colaborativas da ontologia a fazem ser o sistema de organização do conhecimento ideal para a representação dos jogos eletrônicos. Quando associada a uma análise facetada do domínio, a ontologia se torna ainda mais prática de trabalhar, pois a análise facetada oferece previamente um método de estudar o domínio e estabelecer a base taxonômica para o desenvolvimento da ontologia. 


\section{ARTIGO}

- INOVAÇÃo

O resultado experimental do nosso trabalho mostra o grande potencial das ontologias como um sistema de organização do conhecimento que demonstra ter as características necessárias para o tratamento das novas mídias e suportes informacionais nascidos no contexto da Web semântica, que apresenta grande foco nos dados e na automação de softwares, e é decorrência da grande explosão informacional que surge com o advento da Internet. As ontologias têm grande valor na representação do conhecimento, pois essa pode apresentar um número infinito de relações semânticas entre conceitos, tornando-se um instrumento útil para a construção de bases de conhecimento nos mais diversos assuntos em vários domínios de conhecimento. 


\section{REFERÊNCIAS}

ALMEIDA, M. B. Revisiting Ontologies: A Necessary Clarification. Journal of the American Society for Information Science and Technology, New Jersey, v. 64, no 8, p. 1682-1693, 2013.

APPERLEY, T. H. Genre and game studies: Toward a critical approach to video game genres. Simulation \& Gaming, London, v. 37, n. 1, p. 6-23, 2006.

CAMPOS, Maria Luiza Almeida; GOMES, Hagar Espanha. Metodologia de elaboração de tesauro conceitual: a categorização como princípio norteador. Perspectivas em ciência da informação, Belo Horizonte, v. 11, n. 3, p. 348-359, set./dez. 2006. Disponível em: http://www.scielo.br/pdf/pci/v11n3/a05v11n3.pdf. Acesso em: 29 set. 2019.

CLARKE, Rachel Ivy; LEE, Jin Ha; CLARK, Neils. Why Video game genres fail: a classificatory analysis. Games and Culture, London, v. 12, n. 5, p. 445-465, 2015.

DAHLBERG, Ingetraut. Fundamentos teórico-conceituais da classificação. Revista de biblioteconomia de Brasília, Brasília, DF, v.6, n.1, p. 9-21, 1978a. Disponível em: http://www.brapci.inf.br/index.php/res/v/78257. Acesso em: 29 set. 2019.

DAHLBERG, Ingetraut. Teoria do conceito. Ciência da informação, Brasília, DF, v.7, n. 2, p. 101-107, 1978b. Disponível em: http://revista.ibict.br/ciinf/article/view/115/115. Acesso em: 29 set. 2019.

DUARTE, E. A.; CERQUEIRA, R. F. P. de. Análise Facetada: um olhar face a modelagem conceitual. Revista digital de biblioteconomia e ciência da informação, Campinas, v. 4, n. 2, p. 39-52, jan./jun. 2007. Disponível em: http://www.sbu.unicamp.br/seer/ojs/index.php. Acesso em: 6 out. 2019

ELVERDAM, C.; AARSETH, E. Game classification and game design: construction through critical analysis. Games and Culture, London, v. 2, n. 1, p. 3-22, 2007.

GNOLI, C. Metadata about what? Distinguishing Between Ontic, Epistemic and Documental Dimensions in Knowledge Organization. Knowledge Organization, Frankfurt, v. 39, n. 4, 2012.

GRUBER, Thomas R. Toward Principles for the Design of Ontologies Used for Knowledge Sharing. International Journal of Human-Computer Studies, Oxford, v. 43, p. 907-928, ago. 1993. Disponível em: https://tomgruber.org/writing/ontodesign.pdf. Acesso em: 30 out. 2019.

GUARINO, Nicola; OBERLE, Daniel; STAAB, Steffen. What Is An Ontology? In: STAAB, Steffen; STUDER, Rudi. (Org.). Handbook on Ontologies. 2. ed. Berlim: Springer, 2009.

p. 1-17. Disponível em: https://iaoa.org/isc2012/docs/Guarino2009_What_is_an_Ontology.pd f. Acesso em 29 out. 2019.

HJØRLAND, Birger. Theories are knowledge organizing systems. Knowledge

Organization, Frankfurt, v. 42, n. 2, p. 113-128, 2015. 
HJØRLAND, Birger. What is Knowledge Organization (KO)? Knowledge Organization, Frankfurt, v. 35, n. 2, p. 86-101, 2008.

\section{HODGE, Gail. Systems of Knowledge Organization for digital libraries:}

beyond traditional authority files. Washington, DC: The Digital Library Federation, 2000. 37 p. Disponível em: https://www.clir.org/wpcontent/uploads/sites/6/pub91.pdf. Acesso em: 29 set. 2019.

ISOTANI, Seiji; BITTENCOURT, Ig Ibert. Dados abertos conectados. São Paulo: Novatec, 2015. E-book. Disponível em: https://ceweb.br/livros/dadosabertos-conectados/capitulo-3. Acesso em: 3 out. 2019.

LEE, Jin Ha. et al. Facet analysis of video games genres. In: iConference, p. 125-139, 2014. Proceedings [...]. Disponível em: https://www.ideals.illinois.edu/handle/2142/47323. Acesso em: 29 set. 2019.

LIMA, G. N. B. O.; MACULAN, B. C. M. S. Estudo comparativo das estruturas semânticas em diferentes sistemas de organização do conhecimento. Ciência da informação, Brasília, DF, v. 46, n. 1, 2017. DOI: 10.18225/ci.inf..v46i1.4014. Disponível em: http://www.brapci.inf .br/index.php/res/download/55121. Acesso em: 07 out. 2019.

LIMA, José Leonardo Oliveira; ALVARES, Lillian. Organização e representação da informação e do conhecimento. In: ALVARES, Lillian (Org.). Organização e representação da informação e do conhecimento: conceitos, subsídios, interdisciplinaridades e aplicações. São Paulo: B4, 2012. cap. 1.

MILLS, Jack. A modern outline of library classification. London: Chapman and Hall, 1960.

MUNN, K.; SMITH, B. Applied Ontology: an introduction. Frankfurt: Onto Verlag, 2009.

NEEDHAM, C. D. Organizing knowledge in libraries: an introduction to information retrieval. 2nd ed. rev. London: Andre Deutsch, 1971.

NOY, Natalya F.; MCGUINNESS, Deborah L. Ontology development 101: a guide to creating your first ontology. Stanford: Stanford University, 2001. E-book. Disponível em: https://protege.stanford.edu/publications/ontology_development/ontology101.pdf. Acesso em: 3 out. 2019.

PIEDADE, M. A. R. Introdução à teoria da classificação. 2.ed. rev. aum. Rio de Janeiro: Interciência, 1983.

RANGANATHAN, S. R. Colon classification: basic classification. Bombay: Madras Library Association Publication, 1960.

RANGANATHAN, S. R. The five Laws of Library Science. Bombay: Asia Publ. House, 1967.

RESMINI, Andrea; ROSATI, Luca. Semantic retail: towards a cross-context information architecture. Knowledge organization, Frankfurt, n. 35, p. 5-15. 2008. 
ROLLING, Andrew; ADAMS, Ernest. Andrew Rollings and Ernest Adams on GameDesign. London: Pearson, 2003.

ROSA, Malvina Vianna. O papel da classificação na recuperação da informação: classificação facetada. Revista de biblioteconomia de Brasília, Brasília, DF, v.1, n.2, p. 207-210, 1973. Disponível em: http://www.brapci.inf.br/index.php/res/v/77145. Acesso em: 29 set. 2019.

SALDANHA, Ana Alayde; BATISTA, José Roniere Morais. A concepção do role-playing game (RPG) em jogadores sistemáticos. Psicologia: ciência e profissão, Brasília, DF, v. 29, n. 4, p. 700-717, 2009. Disponível em: http://www.scielo.br/scielo.php?script=sci_arttext\&pid $=$ S1414-98932009000400005\&lng=pt\&nrm=iso. Acesso em: 29 set. 2019.

SCHNEIDER, Peer. Origins: The History of IGN. IGN, New York, 11 jan. 2008. Disponível em: https://www.ign.com/articles/2008/01/11/origins-the-history-of-ign. Acesso em: 4 out. 2019.

SMIRAGLIA, R. P. The Elements of Knowledge Organization. Zürich: Springer, 2014.

SOUZA, Lucas Lopes Ferreira de; FREITAS, Ana Augusta Ferreira de. Consumer behavior of electronic games' players: a study on the intentions to play and to pay. Revista de administração, São Paulo, v. 52, n. 4, out./dez. 2017. Não paginado. Disponível em: http://www.scielo.br/scielo.php?script=sci_arttext\&pid=S0080-21072017000400419\&lng=pt \&nrm=iso. Acesso em: 29 set. 2019.

STUDER, R.; BENJAMINS, R.; FENSEL, D. Knowledge engineering: principles and methods. Data \& Knowledge Engineering, Amsterdam, v. 25, n. 1-2, p.161-198, 1998.

VICKERY, B. C. Ontologies. Journal of Information Science, London, v. 23, n. 4, p. 277-286, 1997.

VIGNOLI, Richele Grenge; SOUTO, Diana Vilas Boas; CERVANTES, Brígida Maria Nogueira. Sistemas de organização do conhecimento com foco em ontologias e taxonomias.

Informação \& sociedade, João Pessoa, v. 23, n. 2, p. 59-72, maio/ago. 2003. Disponível em: http://www.brapci.inf.br/index.php/res/download/95993. Acesso em: 29 set. 2019. 


\section{ARTIGO}

INOVAÇÃo

\section{BIBLIOGRAFIA CONSULTADA}

BORST, W. Construction of Engineering Ontologies. $\mathrm{PhD}$ thesis, Institute for Telematica and Information Technology, University of Twente, Enschede, The Netherlands, 1997.

ENGELMANN. Jaqueline. Teoria da definição: das definições reais às definições predicativas. 2006. Tese (Doutorado em Filosofia) - Departamento de Filosofia, Pontifícia Universidade Católica, Rio de Janeiro, 2006.

GOTTSCHALG, Claudio Duque; VILELA, Pedro Junqueira. Ontologias: um tipo único de sistema de organização do conhecimento. In: ENCONTRO NACIONAL DE PESQUISA EM CIÊNCIA DA INFORMAÇÃO, 19., 2018. Anais [...]. Londrina: UEL, 2018. p. 879-899.

Disponível em: http://enancib.marilia.unesp.br/index.php/XIXENANCIB/xixenancib/paper/vi ew/1 053. Acesso em: 29 set. 2019.

GOUGH, Christina. Genre breakdown of video game sales in the United States in 2018.

Statista, 2019a. Disponível em: https://www.statista.com/statistics/189592/breakdown-of-usvideo-game-sales2009-by-genre/. Acesso em: 29 set. 2019.

LEE, Jin Ha; TENNIS, Joseph T.; CLARKE, Rachel Ivy. Domain analysis for a video game metadata schema: issues and challenges. Lecture Notes in Computer Science, Berlin, v. 7489, p. 280-285, 2012. Disponível em: https://www.academia.edu/4350505/Domain_Anal ysis_for_a_Video_Game_Met adata_Schema_Issues_and_Challenges. Acesso em: 29 set. 2019.

SMITH, B.; WELTY, C. Ontology: towards a new synthesis. In: INTERNATIONAL CONFERENCE ON FORMAL ONTOLOGY IN INFORMATION SYSTEMS (FOIS), 2. 2001, Ogunquit. Proceedings [...] New York: Association for Computer Machinery, 2001. p. 3-9. Disponível em: http://mba.eci.ufmg.br/downloads/recol/piii-foreword.pdf. Acesso em: 21 dez. 2019. 